\title{
Decorative 18th Century Blue-and-White Portuguese Tile Panels: A Type-Case of Environmental Degradation
}

\author{
Teresa P. Silva, ${ }^{1}$ Maria-Ondina Figueiredo, ${ }^{1,2}$ \\ Maria-Alexandra Barreiros, ${ }^{3}$ and Maria-Isabel Prudêncio ${ }^{4,5}$ \\ ${ }^{1}$ Unit of Mineral Resources and Geophysics, LNEG, Estrada da Portela, Apartado 7586, 2610-999 Amadora, Portugal \\ ${ }^{2}$ CENIMAT/I3N and Materials Science Department, Faculty of Sciences and Technology, New University of Lisbon, \\ 2829-516 Caparica, Portugal \\ ${ }^{3}$ Unit of Product Engineering, LNEG, Estrada do Paço do Lumiar, 22, 1649-038 Lisbon, Portugal \\ ${ }^{4}$ Instituto Tecnológico e Nuclear, Instituto Superior Técnico (ITN/IST), Universidade Técnica de Lisboa, \\ EN 10, 2686-953 Sacavém, Portugal \\ ${ }^{5}$ GeoBioTec Research Center, University of Aveiro, 3810-193 Aveiro, Portugal
}

Correspondence should be addressed to Teresa P. Silva; teresa.pena@lneg.pt

Received 19 November 2012; Revised 8 January 2013; Accepted 9 January 2013

Academic Editor: Eugen Culea

Copyright (C) 2013 Teresa P. Silva et al. This is an open access article distributed under the Creative Commons Attribution License, which permits unrestricted use, distribution, and reproduction in any medium, provided the original work is properly cited.

\begin{abstract}
Decorated glazed ceramic tiles are used as an ornamental art, constituting an important cultural heritage whose preservation is mandatory. Environmental conditions are responsible for the degradation of exposed ancient tile panels originating various pathologies, related to the development of microorganisms. This is the case of a valuable 18th century blue-and-white Portuguese tile panel called "Cura do Cego," belonging to the collection of the National Tile Museum (MNAz), where green stains are nowadays observable in the glaze. A prospective diagnosis of this green tarnishing was the aim of the present work. Small tile fragments were directly irradiated using nondestructive techniques: X-ray fluorescence spectrometry with a wavelength-dispersive system (WDXRF) for chemical characterization of the tile glaze and X-ray powder diffraction (XRD) to assess the phase constitution of both the glaze and the ceramic body. A destructive technique (scanning electron microscopy with energy-dispersive system (SEM/EDS)) was applied to tentatively infer the chemical changes induced in the glaze by the green staining and also to characterize the morphology of the microorganisms associated to this staining. The obtained results are reported and discussed, as a preliminary step for testing an innovative nondestructive decontamination technique applying gamma radiation, particularly suitable for overcoming such tile pathologies.
\end{abstract}

\section{Introduction}

"Azulejos"-Portuguese word designating glazed ceramic tiles-have been widely used along the last five centuries, covering the interior or placed in the exterior (façades) of churches, monasteries, and palaces, and have been progressively applied in other constructions like particular houses and underground stations [1] linking aesthetic qualities to utilitarian and practical functions.

This valuable cultural heritage deserves nowadays particular attention due to the serious degradation presented by some decorative tile panels, a concern that has pushed the Portuguese National Tile Museum in Lisbon (Museu Nacional do Azulejo (MNAz)) to promote the training of specialized personnel in conservation and restoration in the last decades with the purpose of desirably eliminating the agents responsible for the deterioration of ancient tiles [2].

Many deteriorating environmental effects have been recognized on outdoor glazed ceramics [3].

Most of them are due to rainwater, sun heat, and air currents, but inside the buildings, liquid water and vapor ascending through the porous system of the ceramic body may also give rise to pathologies causing the degradation of the decorative tiles. The formation of soluble salts at 

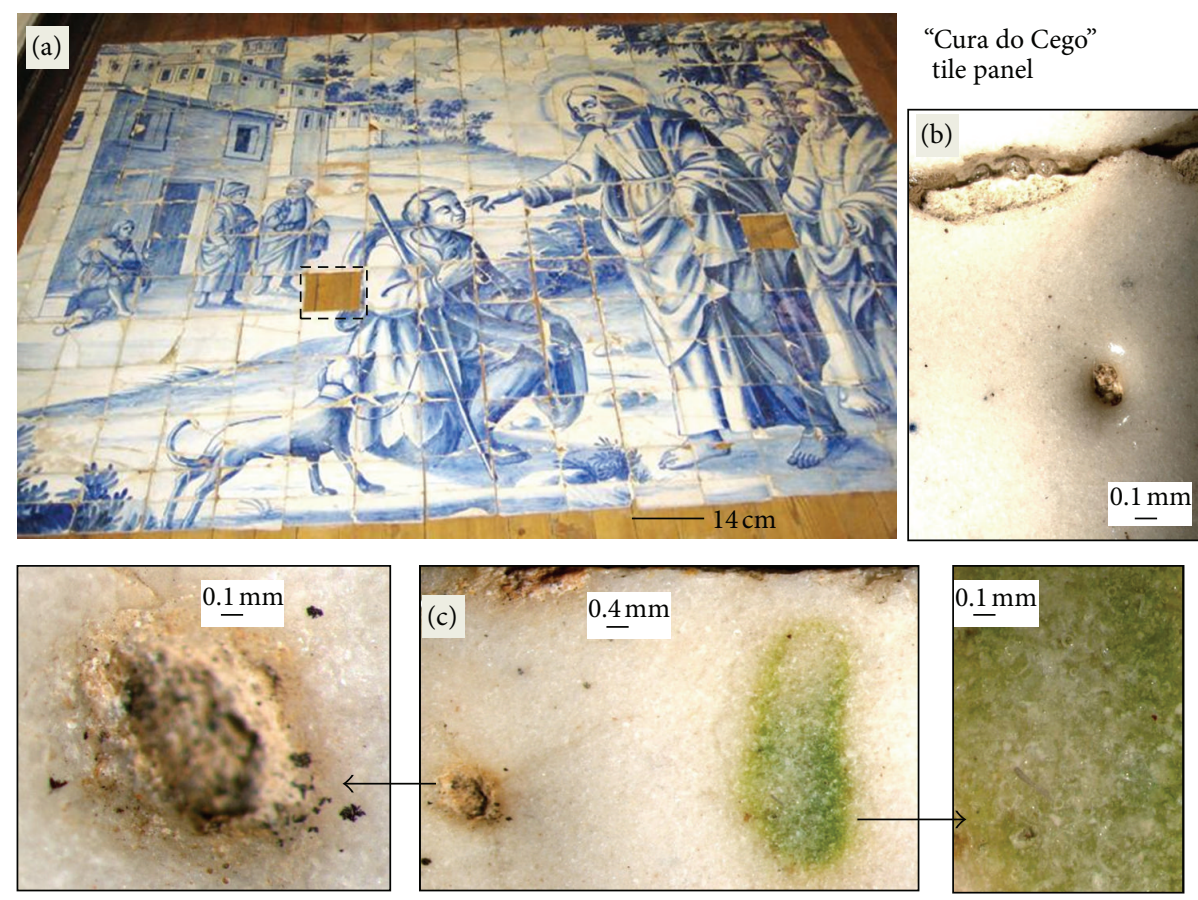

Figure 1: Tile panel "Cura do Cego" (18th century): (a) the location of the studied tile is assigned by a square; (b) and (c) stereomicroscope images collected from a tile fragment showing a consolidated fracture and a hole, plus altered areas (pitting) and green stains.

the surface (efflorescences) and the glaze fracture plus subsequent detachment are among the most harmful outcomes. Furthermore, ancient tile panels exposed to different environmental conditions outside or inside a building are liable to the development of microorganisms: a dark tarnishing observed on the 19th century outdoor polychrome tiles in the Brazilian monuments was ascribed to the simultaneous presence of Cyanophyta and Bacillariophyta algae [4], while the colored alterations noticed in artistic 20th century polychrome tiles covering the façade of an "Art Nouveau" building in Venice were attributed to cryptoendolithic cyanobacteria [5].

Small green stains became recently perceptible in the glaze of blue-and-white tiles from the 18th century Portuguese tile panel called "Cura do Cego" (A Blind Person's Cure) belonging to the collection of the National Tile Museum (MNAz) [6]. Following a previous study on environmental impacts where green stains observed in decorative blue-and-white tile panels manufactured in the 16th century were attributed to the presence of algae colonies [3] and a more recent one focused on the greenish staining developed in the MNAz panel Vista de Lisboa (17th century) restored in the nineties [7], the present work reports a prospective diagnosis of a similar green tarnishing observed in several tiles of "Cura do Cego" panel.

Nuclear methods have been applied for many decades for the chemical characterization of cultural objects [8]. Studies about the air quality inside museums (temperature, humidity, pollutants, and the presence of microorganisms) have been performed to improve the conservation of art works, for example, the Royal Museum of Fine Arts in Antwerp, Belgium [9]. Lately, European museums started to establish specific microbiological monitoring programs; the measurement of fungal spores in the air along the year was an important parameter, and gamma radiation was then appointed as the most effective physical method for killing fungi and their spores [10]. This radiation was applied with success to art objects made of wood [11] and to paintings over canvas [12] but the need for a careful study of materials composition was claimed in both cases. The present study is a preliminary step towards future tile conservation actions involving the use of gamma radiation, along with neutron beams [13], with the purpose of getting rid of microorganisms without damaging that valuable cultural object.

\section{Brief History of the Studied Tile Panel "Cura do Cego"}

The composing tiles of the blue-and-white panel entitled "Cura do Cego" were until recently dispersed in the vast reserve collection of MNAz, when it became possible to identify the panel [6] and integrate it in the museum's permanent collection. The original location of the panel "Cura do Cego" (Figure 1) is yet unknown; nevertheless, the importance attributed to this panel has motivated a previous consolidation and restoration treatment performed at $\mathrm{MNAz}$ (some tiles were very damaged in the borders), along with a prospective diagnosis of the nowadays observed green stains which is described in the present work.

This panel is attributed to an important painter of the Master's Cycle who signed his work with the initials P.M.P. but whose full name is not known and dates from the beginning of the 18th century. This century marked the high point 


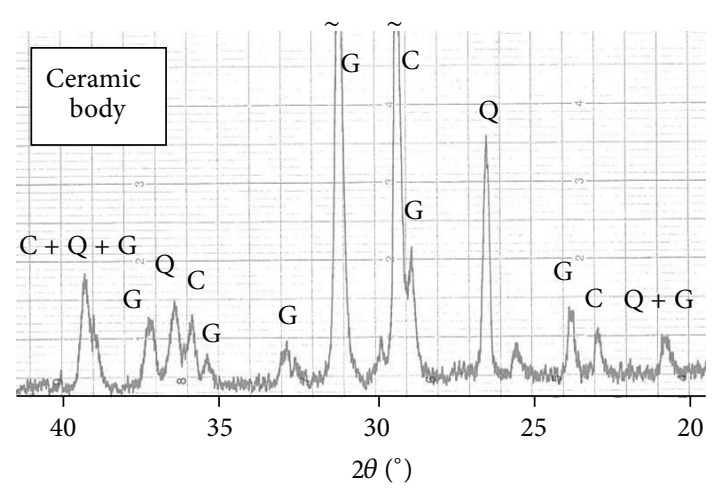

Figure 2: X-ray diffraction pattern of the ceramic body collected by direct irradiation of a tile fragment. Identified crystalline phases: $\mathrm{C}$-calcite $\left(\mathrm{CaCO}_{3}\right), \mathrm{G}$ - gehlenite $\left(\mathrm{CaAl}_{2} \mathrm{SiO}_{7}\right)$, and $\mathrm{Q}-\alpha$-quartz $\left(\mathrm{SiO}_{2}\right)$. The most intense line of each phase is assigned in bold.

of blue-and-white tile manufacture in Portugal (the Cycle of the Masters [14]) and the large-scale production because the imports from Holland forced Portuguese tile workers to improve their standards, involving higher technical demands and the participation of recognized artists in the decorations.

\section{Materials and Methods}

A tile from "Cura do Cego" panel assigned with a square in Figure 1(a)) is the object of the present study. Mainly covered with white glaze, this tile presented small areas of bluish tonality. Observed under a stereomicroscope, a consolidated fracture and a defect like a hole were noticed at the glaze surface (Figure 1(b)). Altered areas (glaze pitting) and large elongated green stains not homogeneously distributed were also observed (Figure 1(c)).

Nondestructive, despite quite invasive, analytical methodologies based on X-rays were preferentially applied; however, the morphological observation of the glaze surface has required the use of a destructive microscopic technique.

3.1. X-Ray Techniques. A Philips PW 1500 powder diffractometer with Bragg-Brentano geometry equipped with a large-anode copper tube operating at $50 \mathrm{kV}-40 \mathrm{~mA}$ and a graphite crystal monochromator was used to collect X-ray diffraction (XRD) patterns for the identification of crystalline components from the ceramic body and to check the eventual development of new phase(s) in the greenish areas as a result of degradation processes of the glaze induced either on the white glaze or on the blue pigment. For that purpose, small tile fragments were directly irradiated in a nondestructive way.

Comparative chemical characterization was performed using an automated Philips PW 1400 wavelength dispersive $\mathrm{X}$-ray fluorescence spectrometer (WDXRF) with X-41 software, equipped with a rhodium tube and operating at $50 \mathrm{kV}$ $45 \mathrm{~mA}$. White and stained zones in the glaze were directly

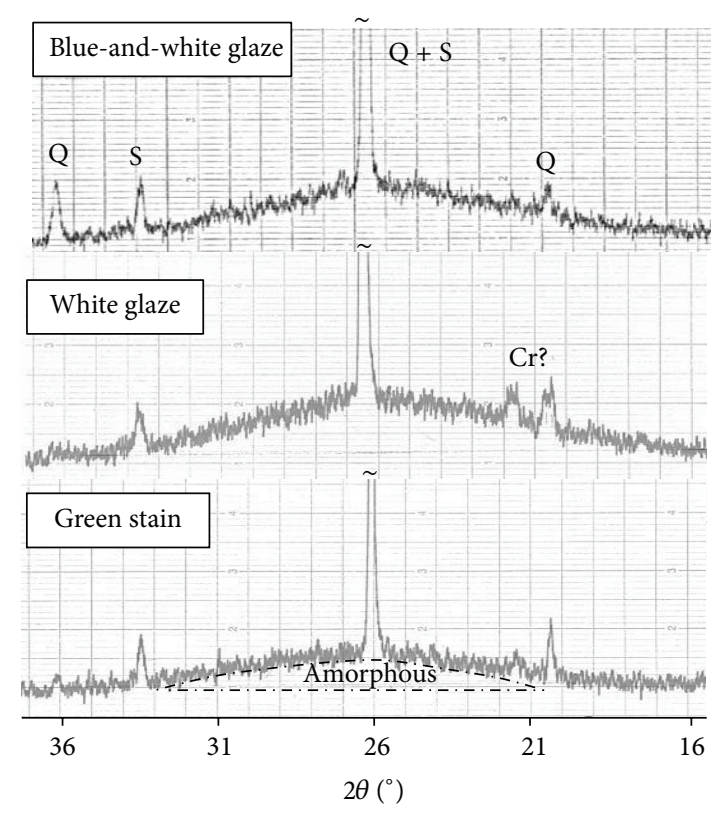

FIGURE 3: XRD patterns obtained for irradiated areas in the studied glaze: blue-and-white glaze, white glaze, and green stain. Identified crystalline phases: $\mathrm{S}$-cassiterite $\left(\mathrm{SnO}_{2}\right) ; \mathrm{Q}-\alpha$-quartz $\left(\mathrm{SiO}_{2}\right) ; \mathrm{Cr}-$ cristobalite $\left(\mathrm{SiO}_{2}\right)$. ?: doubtful identification. The contribution of an amorphous phase is assigned.

irradiated using an appropriate mask to attain a similar analyzed area of about $1 \mathrm{~cm}^{2}$.

Fixed-time countings $(5 \times 10$ seconds) were carried out over the diagnostic X-ray emission lines of relevant elements using an LiF200 analysing crystal. Due to the super position of $\mathrm{Pb} L \alpha$ and $\mathrm{As} K \alpha$ lines, the $K \beta$ line of arsenic and the $L \gamma$ line of lead were also measured to correctly ascertain the presence of each one of these elements. In fact, tile glazes of 16th18 th centuries Portuguese manufacture are based on lead-rich calco-sodic silica glasses with tin oxide as opacifier $[15,16]$.

3.2. Scanning Electron Microscopy. A scanning electron microscope (SEM) Philips XL 30 FEG, with a field emission electron source operated at an acceleration voltage of $10 \mathrm{kV}$, was used to study the morphology and topography of the tile glaze at ambient temperature and under high vacuum. Qualitative elemental analyses were performed with an energy dispersive X-ray spectrometer (EDS) coupled to the microscope.

For the SEM/EDS analyses, the tile fragment was coated with a thin layer of gold in a JEOL ion sputter JFC-1100, thus hindering any further analytical study of the sputtered fragment.

The detector was equipped with a $0.3 \mu \mathrm{m}$ super ultrathin window allowing for the detection of low atomic number elements and characteristic low energy X-ray emission lines (namely, the bioindexing elements carbon and nitrogen, along with oxygen and fluorine). X-ray emission spectra were collected in spot mode analysis (around $3 \mathrm{~nm}$ beam resolution) with 300 -seconds acquisition time. 


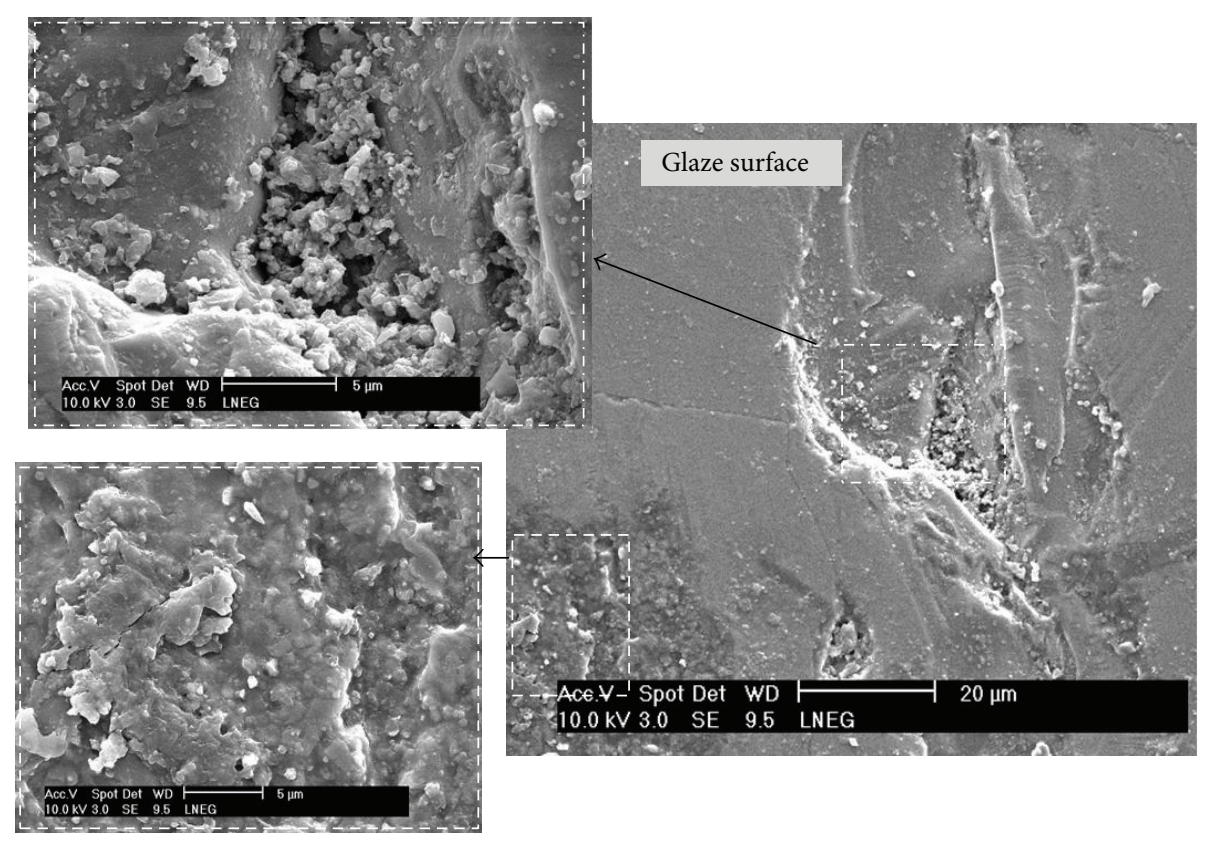

FIGURE 4: SEM image of a corroded area at the surface of the white glaze and details of the selected areas.

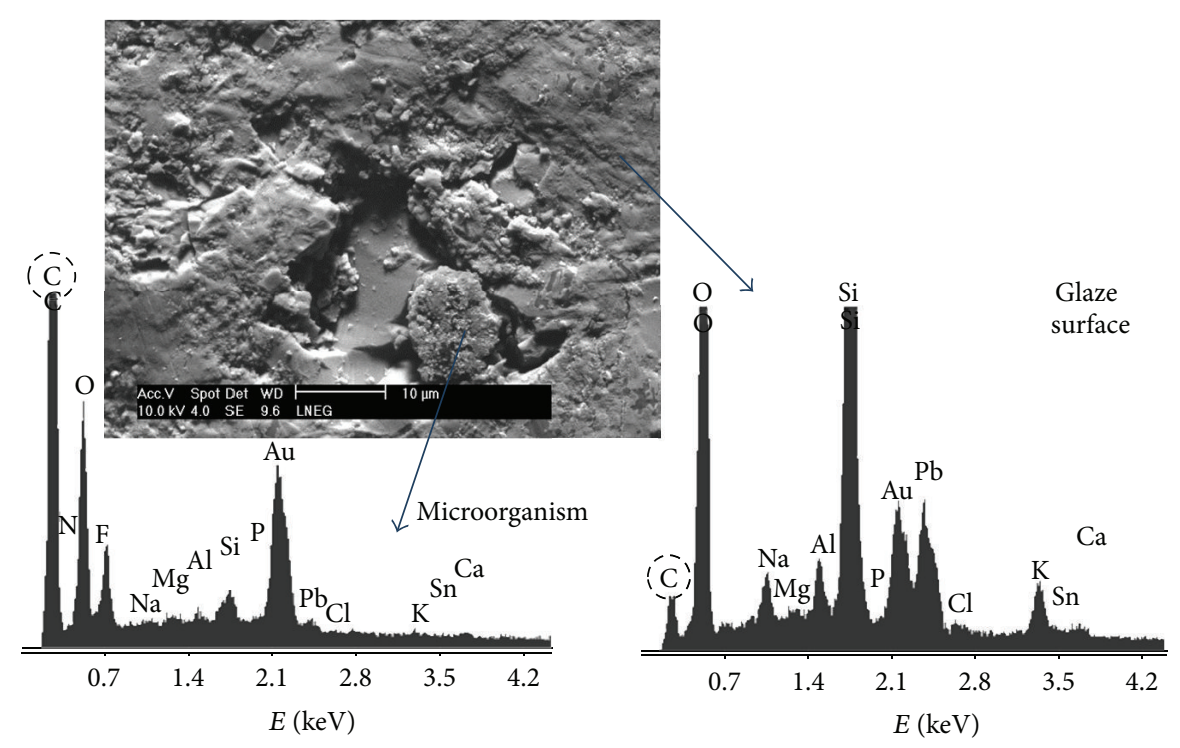

FIGURE 5: Comparison of SEM/EDS spectra collected from a microorganism in a corroded area and from the white glaze surface.

\section{Results and Discussion}

The mineralogical constitution of the ceramic body was characterized by X-ray diffraction. As expected for common ancient whitish ceramics [3], the main constituting phases (Figure 2) are quartz $\left(\mathrm{SiO}_{2}\right)$ and a member of the gehleniteäkermanite series $\left[\mathrm{Ca}_{2} \mathrm{Al}_{2} \mathrm{SiO}_{7}-\mathrm{Ca}_{2} \mathrm{MgSi}_{2} \mathrm{O}_{7}\right]$, plus calcite $\left(\mathrm{CaCO}_{3}\right)$. XRD patterns of the glaze (white and bluish) and of the surface green stain are very similar (Figure 3): the crystalline phases present are cassiterite $\left(\mathrm{SnO}_{2}\right)$-the opacifier currently used to manufacture tile glazes in the 17 th18 th century-and quartz.

The low temperature form of silica (cristobalite) is possibly present (assigned as $\mathrm{Cr}$ in the XRD pattern of the white glaze, Figure 3), denoting the ageing of the glaze-a degradation process that starts with a partial devitrification of the siliceous glassy matrix [3].

An amorphous contribution due to the vitreous component (a siliceous lead-rich glass) is observed in all XRD patterns. 
TABLE 1: WDXRF elemental data with reference to the glaze.

\begin{tabular}{|c|c|c|c|}
\hline Element & $2 \theta^{\circ}$ & White area & Stained area \\
\hline Background & 134.0 & 900 & 919 \\
\hline $\mathbf{K}^{*} K \beta$ & 118.5 & 9062 & 8466 \\
\hline $\mathbf{S n}^{\#} L \beta$ & 114.4 & 4836 & 5582 \\
\hline $\mathrm{Ca}^{*} K \alpha$ & 113.1 & 21692 & 17662 \\
\hline Ti $K \alpha$ & 86.14 & 897 & 857 \\
\hline Background & 84.00 & 257 & 273 \\
\hline Fe $K \alpha$ & 57.52 & 64669 & 64511 \\
\hline Zn $K \alpha$ & 41.80 & 7643 & 7668 \\
\hline As $K \alpha+\mathbf{P} \mathbf{b}^{\#} L \alpha$ & 34.00 & 148213 & 160001 \\
\hline As $K \beta$ & 30.45 & 3764 & 3756 \\
\hline $\mathbf{P b}^{\#} L \gamma$ & 24.07 & 17200 & 17479 \\
\hline Background & 21.50 & 2794 & 2710 \\
\hline
\end{tabular}

${ }^{*}$ Decrease.

" Increase.

Table 1 lists the comparative data for the rough chemical characterization of the green stained area taking the white glaze data as reference. Averages of five measurements obtained by WDXRF over each diagnostic line and over the corresponding selected background are listed.

The high lead content, combined with tin, confirms that the glaze is a lead-rich glass with cassiterite added as opacifier.

The relative contents of potassium and calcium decrease in the green stains, while tin and lead increase. This may arise from the ability of microorganisms to concentrate toxic metals, a feature recognized for so long [17], along with the associated bio-deterioration mechanisms, chemical and/or physical.

While the degradation of stone monuments by fungi, algae, or bacteria has been extensively evaluated (e.g., [18]), little is known about the behaviour of glazed ceramics from external decorative panels relative to the "attack" of microorganisms.

Collected SEM images (Figure 4) illustrate the morphology of altered and corroded areas (the so-called "pitting") observed at the glaze surface.

X-ray emission spectra reproduced in Figure 5 compare the bulk elemental constitution of the glaze surface to that of a green stain. As expected, the contents of oxygen, silicon, and lead are high in the glaze; on the other hand, the strong emission line of carbon and the vestigial occurrence of nitrogen in the small aggregate lodged at the altered glaze surface conform to the presence of microorganisms.

\section{Final Comments}

The use of nondestructive methodologies based on X-rays by directly irradiating small tile fragments without any further preparation is the most suitable way to evaluate the degradation state of ancient tiles with great cultural value. A smoky tarnishing of the glaze noticed after irradiating the tile fragments for XRD and WDXRF analyses signifies that these nondestructive assays are nevertheless quite invasive, at least temporarily. Conversely, the observation under a scanning electron microscope implies the coverage of the cultural artifact with a non-removable metallic deposit but allows for comparing the contents of elements with low atomic number indicating the presence of microorganisms, namely, carbon and nitrogen.

The present study confirms that the bulk constitution of blue-and-white glazes from 18th century tiles was not significantly affected-neither chemically nor in phase constitution-by the green staining due to the development of microorganisms' colonies. These results are in agreement with previous observations concerning ancient tile glazes of Portuguese manufacture, either in Portugal [3] or in Brazil [4], as well as with the staining observed in recently restored 20th century "Art Nouveau" polychrome tiles subjected to intense humidity in Venice, Italy [5].

The noticed corrosion or pitting of the lead-rich glaze, observed by SEM, is understandable in view of the recognized biosorption of lead by fungi or algae-an attribute that nowadays is even technologically applied [19]. As an attempt to identify these microorganisms-algae, fungi, and bacteria-laboratorial cultures are at present under preparation. Another step currently in progress is the application of conservation treatments using gamma radiation, an innovative nondestructive decontamination technique particularly suitable for dealing with the development of microorganisms.

\section{Conflict of Interests}

The authors declare that there is no conflict of interests in using commercial identities as "Philips PW 1500 powder diffractometer," "Philips PW 1400 wavelength dispersive Xray fluorescence spectrometer," "Philips XL 30 FEG scanning electron microscope," and "JEOL ion sputter JFC-1100" in the present work.

\section{Acknowledgments}

The work developed within the project RADIART (PTDC/ HIS-HEC/101756/2008) is financed by the Portuguese Foundation for Science and Technology. The author affiliated to CENIMAT/I3N acknowledges the financial support of FCTMCTES through the Strategic Project LA25-2011-2012 (ref. PEst-C/CTM/LA0025/2011).

\section{References}

[1] J. Meco, The Art of Azulejo in Portugal-Portuguese Glazed Tiles, Bertrand Editora, 1988.

[2] J. C.-B. Pereira, M. M. M. Gomes, and D. A. Tavares, "The treatment of ancient Portuguese tiles," in Conservation of the Iberian and Latin American Cultural Heritage, H. W. M. Hodges, J. S. Mills, and P. Smith, Eds., pp. 112-115, IIC, London, UK, 1992.

[3] M. O. Figueiredo, T. P. Silva, and J. P. Veiga, "Ancient glazed ceramic tiles: a long-term study from the remediation of environmental impacts to the non-destructive characterization of materials," in Proceedings of the International Seminar on Conservation of Glazed Ceramic Tiles: Research and Practice, LNEC, Ed., p. 10, Lisbon, Portugal, 2009. 
[4] M. M. Oliveira, T. B. C. Sanjad, and C. J. P. Bastos, "Biological degradation of glazed ceramic tiles," in Historical Constructions, P. B. Lourenço and P. Roca, Eds., pp. 337-341, Guimarães, Portugal, 2001.

[5] L. Giacomucci, R. Bertoncello, O. Salvadori et al., "Microbial deterioration of artistic tiles from the façade of the Grande Albergo Ausonia \& Hungaria (Venice, Italy)," Microbial Ecology, vol. 62, no. 2, pp. 287-298, 2011.

[6] J. Bragança, “"A Blind Person's Cure”-an unknown tile panel from the Collection of the National Tile Museum," in Thematic Network of Studies on Tiles and Ceramics, 2011.

[7] T. P. Silva, M. O. Figueiredo, M. A. Barreiros, and M. I. Prudêncio, "Pathologies in ancient (17th-18th Century) decorative tiles: green stains in the blue-and-white glazes of a panel figuring Lisbon prior to the 1755 earthquake," Studies in Conservation. In press.

[8] M. I. Dias and M. I. Prudêncio, "Neutron activation analysis of archaeological materials: an overview of the ITN NAA Laboratory, Portugal," Archaeometry, vol. 49, no. 2, pp. 383-393, 2007.

[9] K. Gysels, F. Delalieux, F. Deutsch et al., "Indoor environment and conservation in the Royal Museum of Fine Arts, Antwerp, Belgium," Journal of Cultural Heritage, vol. 5, no. 2, pp. 221-230, 2004.

[10] K. Sterflinger, "Fungi: their role in deterioration of cultural heritage," Fungal Biology Reviews, vol. 24, no. 1-2, pp. 47-55, 2010.

[11] L. C. Severiano, F. A. R. Lahr, M. A. G. Bardi, A. C. Santos, and L. D. B. MacHado, "Influence of gamma radiation on properties of common Brazilian wood species used in artwork," Progress in Nuclear Energy, vol. 52, no. 8, pp. 730-734, 2010.

[12] M. M. Rizzo, L. D. B. Machado, P. R. Rela, and Y. Kodama, "Gamma rays irradiation process on a restored painting from the XVIIth century," in Proceedings of the International Nuclear Atlantic Conference (INAC '09), Associação Brasileira de Energia Nuclear, Ed., p. 7, Rio de Janeiro, Brazil, 2009.

[13] M. I. Prudêncio, M. A. Stanojev-Pereira, J. C. Marques et al., "Neutron tomography for the assessment of consolidant impregnation efficiency in Portuguese glazed tiles (16th and 18th centuries)," Journal of Archaeological Science, vol. 39, no. 4, pp. 964-969, 2012.

[14] "18th century. Tiles imported from Holland, Cycle of the Masters and Large-scale Production," Museu Nacional do Azulejo, 2009, http://mnazulejo.imc-ip.pt/en-GB/ExhibitAct/ PermExhibit/ContentDetail.aspx?id=437.

[15] M. O. Figueiredo, T. P. Silva, and J. P. Veiga, "A XANES study of the structural role of lead in glazes from decorated tiles, XVI to XVIII century manufacture," Applied Physics A, vol. 83, no. 2, pp. 209-211, 2006.

[16] M. O. Figueiredo, J. P. Veiga, and T. P. da Silva, "Ageing of highlead glazes in XVI-XVII century tiles," in Proceedings of the International Conference on Non-Destructive Testing and MicroAnalysis for the Diagnostics and Conservation of the Cultural and Environmental Heritage, R. Van Grieken, K. Janssens, L. V. Dack, and G. Meersman, Eds., p. 8, Antwerp, Belgium, 2002.

[17] C. White, S. C. Wilkinson, and G. M. Gadd, "The role of microorganisms in biosorption of toxic metals and radionuclides," International Biodeterioration and Biodegradation, vol. 35, no. 1-3, pp. 17-40, 1995.

[18] M. F. Macedo, A. Z. Miller, A. Dionísio, and C. Saiz-Jimenez, "Biodiversity of cyanobacteria and green algae on monuments in the Mediterranean Basin: an overview," Microbiology, vol. 155, no. 11, pp. 3476-3490, 2009.

[19] V. K. Gupta and A. Rastogi, "Biosorption of lead from aqueous solutions by green algae Spirogyra species: kinetics and equilibrium studies," Journal of Hazardous Materials, vol. 152, no. 1, pp. 407-414, 2008. 

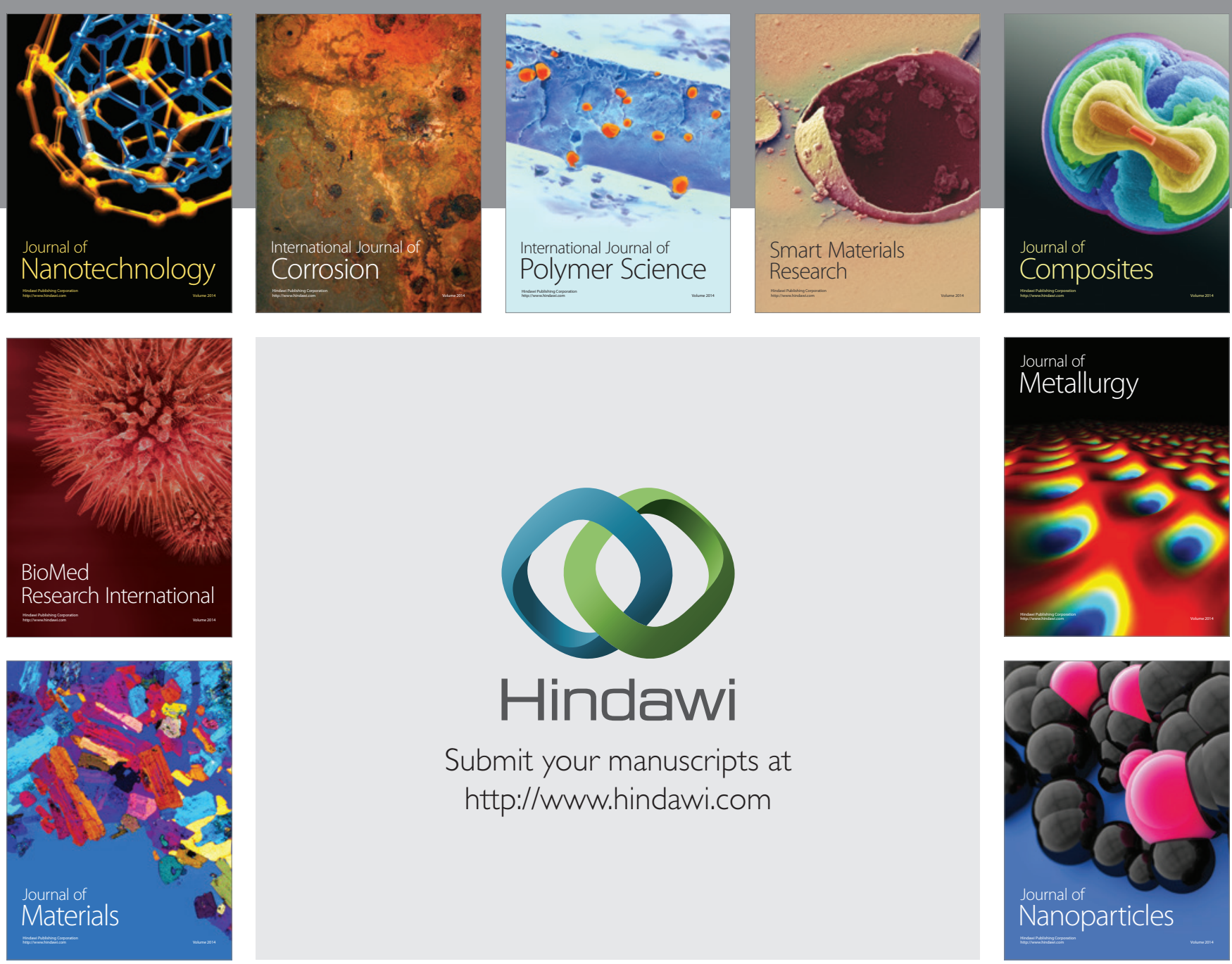

Submit your manuscripts at http://www.hindawi.com
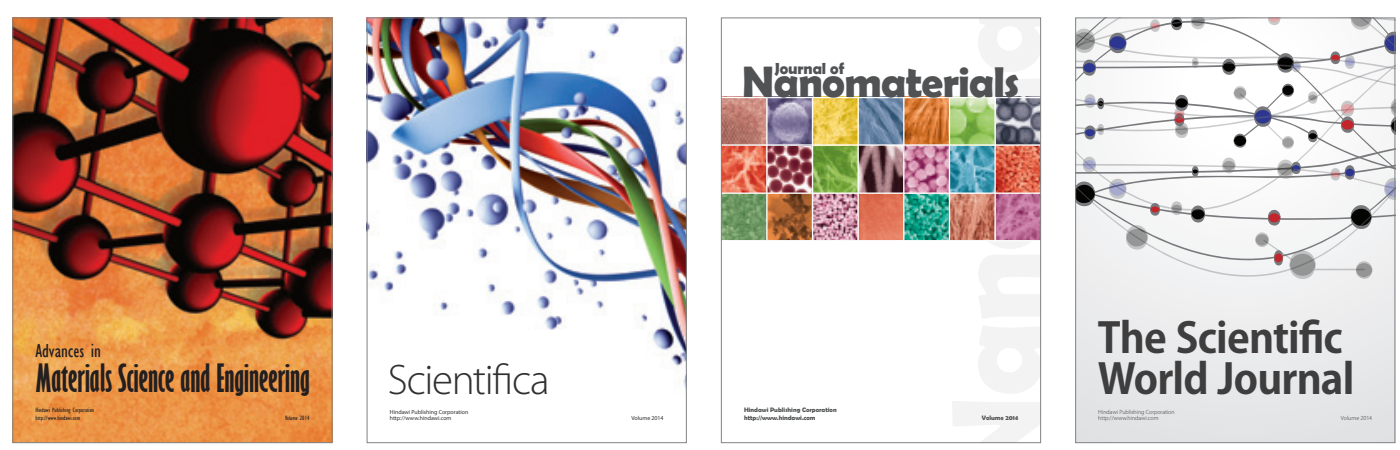

\section{The Scientific World Journal}
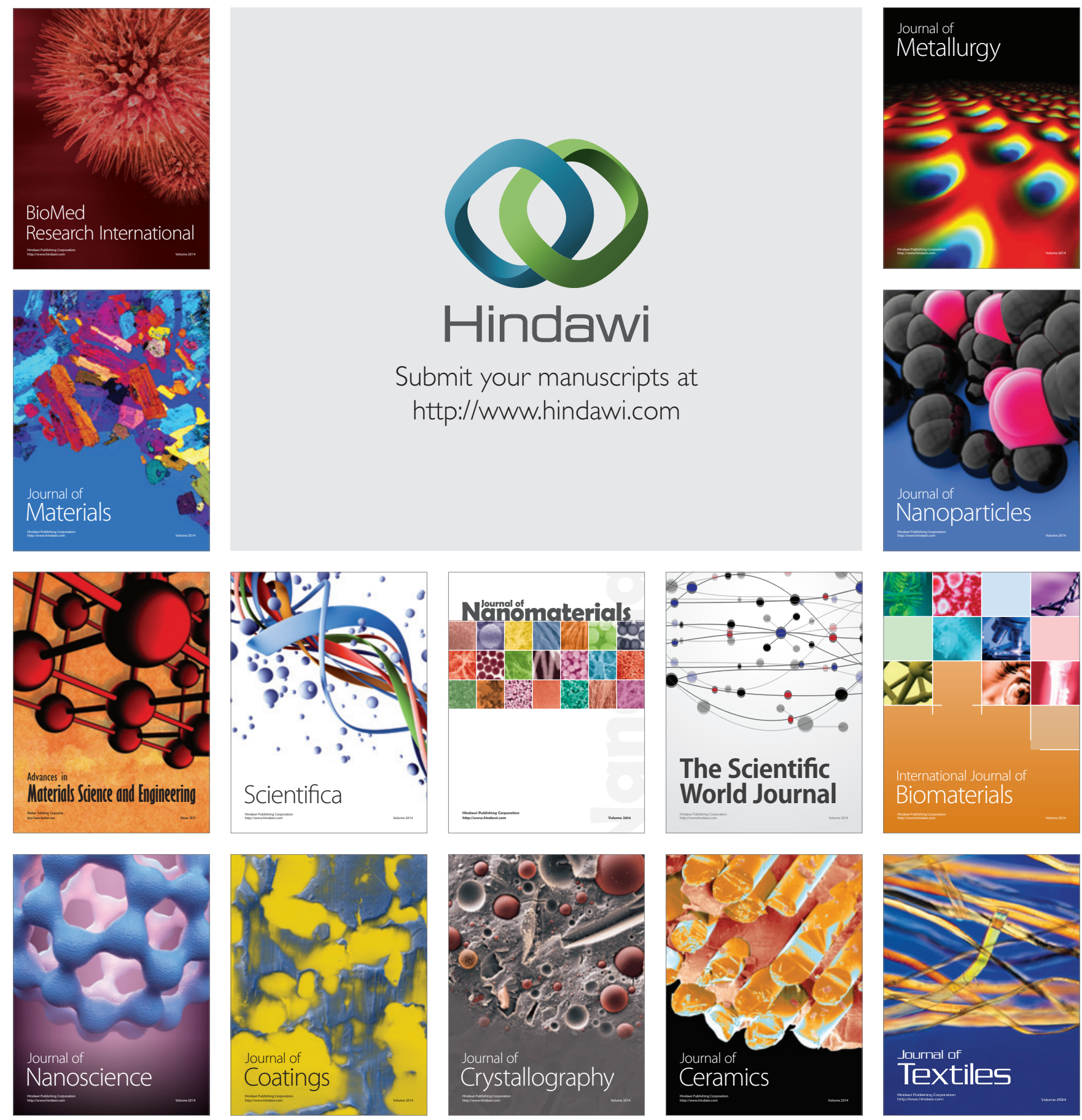